\title{
El confucianismo en Corea
}

$\mathrm{E}$ $\mathrm{n}$ la actualidad, Corea (en adelante así, pero refiriéndome a la sureña)ha sido calificada como la nación más influenciada por las ideas de Confucio. En la región del este asiático diversas naciones han adoptado el confucianismo en variadas modalidades y épocas. En Corea, especialmente, esta filosofía fue introducida cuando el budismo ya se encontraba en decadencia y se necesitaba una renovación tanto en el sistema de gobierno como en la administración de la justicia. Como resultado, el confucianismo se convirtió en un régimen de vida social y política que llegó a enraizarse hasta tener una evidente presencia en las maneras de socialización de la sociedad coreana de nuestros días. Este trabajo pretende esbozar brevemente el confucianismo, luego de su introducción a Corea en la época de los Tres Reinos (siglo VI), para después describir su adaptación y desarrollo y finalizar con la manera en que este conjunto de valores ha llegado a permear las costumbres y tradiciones de los coreanos en la época actual.

\section{Principios básicos del confucianismo en su origen}

Se define al confucianismo como un sistema complejo de enseñanzas morales, sociales y políticas definidas y estudiadas por Confucio (K'ung-fu-tze, 551 a.C.-478 a.C.). Confucio mostró desde su infancia una especial actitud

\footnotetext{
* Pasante en la maestría del área de estudios coreanos, Escuela de Estudios Internacionales y Regionales, Universidad Nacional de Seúl
}

hacia el estudio. A la edad de 22 años fundó una escuela que pronto adquirió fama debido a sus especiales enseñanzas. Pronto fue promovido como ministro de justicia gracias a su habilidad y servicio. Bajo su sabia administración, el Estado alcanzó un nivel de prosperidad y moral nunca antes visto en China. Finalizó su servicio como ministro por intrigas de sus enemigos y a partir de entonces se dedicó a predicar sus principios viajando por diversas regiones.

Entre los textos que forman la base del confucianismo existen algunos que en tiempos de Confucio ya se veneraban como reliquias sagradas el pasado, y que incluyen ritos y costumbres que él mismo sancionó o aprobó. Los textos confucianos se dividen en dos categorías: Los clásicos y Los libros. Entre estos está el Librode historia que es una serie trazada de grandes eventos del pasado e inculca la lección de que el Dios-Cielo otorga prosperidad y larga vida solamente a los gobernadores virtuosos que se han preocupado por conservar los bienes de su gente como algo sagrado. Existe otro libro llamado de los cantos, que incluye 305 poemas. El Libro de los cambios es un tratado sobre el arte de la adivinación utilizando de una planta autóctona. Le sigue el Libro de los ritos que está formado por una compilación de una considerable cantidad de documentos en los que se detallan los actos religiosos de ofrenda, funciones de la corte, relaciones sociales y familiares, formas de vestir, etcétera, y que forman las reglas para todo aspecto de la vida común. Asimismo, están incluidos los Analectos, que describen la manera en que se conducía 
Confucio en la vida diaria y sus sermones sobre la moral.

En cuanto a la doctrina del confucianismo, ésta afirma que existen numerosos espíritus asociados entre sí, tales como las montañas, los ríos, los cielos, el sol, la luna, la tierra y sus frutos, los cuatro puntos cardinales, y que todos están subordinados al Dios-Cielo. Otro fundamento pseudorreligioso para promover la práctica virtuosa es la creencia de que los espíritus de los parientes fallecidos dependen de la conducta de sus parientes en vida para obtener la felicidad.

Varias afirmaciones eran también utilizadas para promover la virtud. Entre otras está la que promueve el estudio y la entrega a la lectura como arma contra la ignorancia y que es -según Confucio- una guía infalible hacia la virtud. Confucio también promovía la amistad con los más "virtuosos" y urgía a sus discípulos a corregirse entre ellos sus propias faltas en forma fraternal.

Las cuatro virtudes nucleares del confucianismo son: la sinceridad, la benevolencia, la piedad filial y la propiedad. En cuanto a las observancias ceremoniales, se pueden mencionar seis en total: la puesta de sombrero (que consiste en otorgarle al hijo varón un sombrero especial que tendrá que llevar en la vida diaria significando que ya se ha convertido en un hombre), el matrimonio, los ritos mortuorios, los sacrificios, las fiestas y las entrevistas. En la mayoría de estos eventos se ofrece comida sobre un altar para honrar a los espíritus invitados.

En cuanto a la política, el confucianismo decreta que el rey, quien gobierne al pueblo, tiene una autoridad absoluta sobre sus plebeyos y ésta es otorgada por derecho divino, tal como el padre gobierna sobre sus hijos. Era el Cielo quien lo designaba para iluminar a su pueblo con leyes sabias y para que los guiara hacia la bondad con su ejemplo y autoridad.

\section{Llegada del confucianismo a Corea y su evolución}

Como hemos dicho, el Confucianismo fue introducido a Corea durante la época llamada de los Tres Reinos que abarca desde el siglo I d.C. hasta finales del VII. Dichos reinos eran Koguryo (dominando la parte norte de la península), Shila (con posesión de toda la costa occidental y parte central) y Paekche (al extremo sureste). La nueva corriente cultural venida de China fue aceptada gradualmente, y en ciertos momentos rechazada, por cada uno de los reinos en periodos diferidos, pero al final llegó a dominar toda la península con la unificación de los reinos.

La ideología en cuestión pronto fue llamada "religión de Estado" y tuvo como consecuencia inmediata una racionalización de la estructura y organización de la sociedad con base en una ideología patrilineal. Los lazos consanguíneos formaron la estructura social. Es por esto que los individuos eran clasificados conforme su grupo familiar de ascendencia. Dicho grupo veneraba a un ancestro y llevaba su apellido seguido por el nombre del lugar de origen. Ya que se practicaba la exogamia, el primer hijo de la primera esposa tenía el lugar y la preferencia sobre los demás hijos de la misma mujer y de las demás esposas.

Tal factor era crucial para la persona que pretendiera obtener un lugar en la estructura gubernamental o para crear alianzas matrimoniales. Sin embargo, las hijas sólo obtenían un nombre (formal) cuando contraían matrimonio. Debido a ello, las genealogías fueron convirtiéndose en grandes grupos de descendencia bastante complejos. En muchas ocasiones era imposible incluir a todos los miembros familiares en una sola línea descendente y surgían conflictos entre grupos que después se separaban para formar un nuevo linaje. La prominencia social, política y económica era obtenida solamente a través de un linaje propiamente certificado.

Los aristócratas coreanos (yangban) obtenían su título solamente por herencia, de 
tal manera que existía un control efectivo de acceso al poder político. Tal herencia determinaba la elegibilidad para los exámenes "públicos" y eran los aristócratas quienes ocupaban los rangos más altos en el gobierno. El criterio entonces era la pertenencia a una línea de descendientes que viniera de un "ancestro distinguido", y la distinción correspondía a la reputación académica. Los aristócratas también poseían grandes tierras y generalmente disfrutaban del prestigio y la cultura confuciana que les era conferida.

La expresión ritual que manifestaba mejor la pertenencia a un linaje era la reverencia a los ancestros. Dicho evento era llevado a cabo por el grupo descendiente que correspondía a cinco niveles distintos de cercanía sanguínea de un tatarabuelo común, observando ritos funerarios. Dichos ritos se celebraban en un altar donde también se conservaban las tablas ancestrales. Las ceremonias eran temporales y estaba implícito que los primogénitos representantes de cada grupo descendiente de un ancestro se reunieran durante días. Es así como se fueron formando pequeñas aldeas por linajes únicos; usualmente en el centro de estas comunidades se encontraba la "casa mayor" rodeada de otras pequeñas siguiendo el orden de jerarquía familiar. Estas tenían un orden que correspondía a los principios confucianos, de manera que los dormitorios eran divididos y las mujeres y los hombres dormían en partes separadas entre sí por pabellones.

En cada comunidad existía un consejo que era dirigido por el mayor de edad y que decidía cuestiones tales como finanzas, tumbas ancestrales, destitución de miembros del linaje, compilación y enmiendas de los registros genealógicos. Otro tipo de organizaciones también eran creadas para los asuntos de educación, solidaridad y cooperación. La base económica de cada linaje estaba formada por esclavos, territorios, bosques y edificios o casas.

Las clases sociales inferiores a los aristócratas estaban organizadas en dos rangos: los comuneros (quienes estaban obligados a pagar impuestos y ejercer el servicio militar, y quienes alrededor del siglo XVII fueron adquiriendo prominencia económica con el surgimiento del comercio), y la gente de clase baja, a la que pertenecían esclavos, carniceros, peleteros y shamanes. La clase social siempre fue adquirida por nacimiento. La estructura legal y las costumbres sociales impedían cualquier esfuerzo por trasgredir tales barreras.

Es así como fue concebida la sociedad por los coreanos durante siglos, afectando profundamente tanto al status de las clases sociales inferiores como a las mujeres en general, debido al fuerte patriarquismo constantemente reforzado.

\section{La introducción del neoconfucianismo y su desarrollo}

El primer contacto de Corea con el confucianismo renovado que surgió del sur de China, fue a través de relaciones matrimoniales que comenzaron a existir entre la casa imperial mongola y la familia real de Koryo. El rey coreano Chungnyol (1274-1308) contrajo nupcias con la hija de Khubilai. De tal matrimonio nació el rey Chungson quien se dedicó a propagar activamente esta nueva corriente.

El neoconfucianismo consistió en una especie de "aprendizaje concreto". Es decir que la virtudes debían ser llevadas a la práctica no sólo a través de la concentración y el estudio de los libros, sino que dichos principios debían manifestarse en las acciones de quien los predicara.

Una clave dentro de esta transformación estuvo en la manera de efectuar los ritos ceremoniales. Los ritos son actos "correctos" en la manera de comportarse que ejercen una profunda influencia en la disposición interna del hombre. En la reverencia a los ancestros se demuestra cómo las cosas deben ser hechas correctamente y también es considerada un método para crear armonía entre los participantes. Así, los ritos corresponden no tanto al individuo sino que aún van más allá hasta incluir a la familia colectiva y, en un sentido más amplio, a la sociedad. Es de esta 
manera como se crea el principio surgido de las relaciones humanas que forman parte del orden normativo sociopolítico. Los modelos de comportamiento de los ritos perfectos y el rígido orden sociopolítico estan incluidos en los trabajos a los que Confucio se dedicó en forma exhaustiva.

\section{El confucianismo coreano en la sociedad moderna}

Como ya se describió, el confucianismo, más que tener una presencia física, se manifiesta a través de la conciencia, los patrones de comportamiento y las instituciones de la sociedad. A partir de la Segunda Guerra Mundial muchos cambios sociales han tenido lugar, principalmente en el área lingüística, por lo que la herencia nacional, la identidad y las tradiciones culturales se han transformado significativamente. La llegada de la civilización occidental trajo a la región asiática nuevos vocablos y muchos tuvieron que ser creados o adoptados.

Aunque dentro del confucianismo existe cierto tipo de religiosidad con referencia al Cielo como observador omnipresente y omnipotente y juez de la conducta humana, esta filosofía no es considerada una religión como tal. Es por eso que a lo largo de su historia ha convivido con religiones como el budismo, el taoísmo, el cristianismo, etc.

La invasión occidental en el este asiático fue rechazada durante tres siglos y en determinado momento China, Japón y Corea fueron buscando su manera de resistirla. En Japón se inició una apertura total a partir de 1868 con una rápida adopción de las instituciones y tecnologías de Occidente. Corea, en contraste, se expuso menos a las nuevas corrientes ideológicas debido a su rígida política de aislamiento, aunada a su apatía hacia el comercio y su ubicación geográfica lejana de las rutas marinas. Por consecuencia, la occidentalización de Corea fue realizada en un principio por los invasores japoneses quienes ya venían "occidentalizados". Durante la Colonia Japonesa en Corea (1910-1945), la forma de gobierno y las instituciones sociales fueron forzadas a cambiar. Ante el proceso de occidentalización, los coreanos insistían en conservar un espíritu de "sustancia oriental con técnicas occidentales". Tal dicotomía no duró mucho tiempo ya que la "sustancia occidental" no puede ser separada de la ciencia, la tecnología y la industria occidentales. Es así como la tradición confuciana dejó de ser una ideología de Estado y quedó confinada en los ritos y en la ética familiar. Así ha permanecido hasta nuestros días con cambios que se han venido dando muy lentamente. Sin embargo, a partir de la industrialización gradual y el proceso de modernización, los elementos confucianos han recibido constante presión.

Entre los investigadores que han analizado esta filosofía hay quienes afirman que constituye un gran obstáculo para la modernización de las naciones del este asiático, y otros, por el contrario, consideran que fue la que favoreció el gran desarrollo económico que estas naciones mostraron durante las últimas décadas del siglo veinte.

Desde que se liberaron de la Colonia Japonesa, la corriente política predominante ha sido en pro de una democracia total y una negación del pasado heredado. El nacionalismo coreano se ha basado en el orgullo de haber repelido en innumerables ocasiones las invasiones extranjeras, así como en sus invenciones científicas y artísticas, pero hay en el poca referencia al confucianismo. Desde entonces, los intelectuales se han dedicado a hacer notar los defectos y males de las tradiciones confucianas. No obstante, la gente ha continuado discretamente las normas tradicionales, como los matrimonios arreglados por las familias y no por los individuos implicados, las ofrendas a los ancestros, el respeto estricto a los mayores, la piedad filial y la subordinación de las mujeres, en cierta medida todavía notable. Aun los budistas y los cristianos se incluyen entre la población que efectúa largos periodos de duelo y ofrece sacrificios a sus ancestros en las tumbas de las montañas todos los otoños. Hasta hoy subsiste también una universidad privada dedicada a los estudios confucianos. Asimismo existe una organización integrada por algunos 
descendientes de aristócratas que promueve activamente la conservación de los principios confucianos en el régimen legal pero que, desde la toma de poder de Kim Dae-Jung, ha venido perdiendo reconocimiento y poder.

Los valores y la moralidad confucianos, como tales, se oponen al desarrollo y las reformas modernas, pero dichos valores y actitudes han contribuido de una manera no intencionada a consolidar los esfuerzos nacionales a favor del desarrollo. En particular después de 1931, los patrones de vida y trabajo comenzaron a cambiar. Aún antes de la industrialización de los años 30 y 40 y del crecimiento significativo que sufrió la fuerza de trabajo urbana, Corea siguió siendo una nación predominantemente agraria ya hasta entrados los 50 . La sociedad rural fue alterada por las reformas territoriales de 1948 y 1950, y lo que tuvo mayores efectos fue la guerra coreana que afectó en gran medida las diferencias de clase y estimuló el crecimiento demográfico.

Durante las últimas tres décadas del siglo veinte la industrialización propició la movilización masiva desde el campo hacia las fábricas y de los pequeños pueblos a las grandes ciudades. Como consecuencia de tales cambios en la forma de vida y trabajo de los coreanos no se ha podido evitar una gran presión sobre el sistema tradicional de valores. Sin embargo, los valores confucianos continúan enraizados en las relaciones interpersonales, en el ámbito familiar y en el trabajo.

Desde el incicio de la segunda mitad del siglo veinte, la política estatal se ha dedicado al problema de la construcción nacional, lo que provocó un cambio en el diálogo sobre el pasado confuciano. Sin embargo, los políticos siguieron recurriendo a la lealtad que el confucianismo promueve para reforzar la identificación de la gente con el Estado y convertir dicho valor en patriotismo.

Aunque el sistema gubernamental de Corea tenga la voluntad de usar indirectamente los valores confucianos de lealtad y servicio, este se rehusa a seguir las tradiciones como tales, pues existe la idea general de que sólo sirven para detener el desarrollo económico. Como ejemplo podemos poner la administración de Park Chung Hee (1961-1979), bajo la cual se criticaron arduamente tales tradiciones y se afirmaba abiertamente que esta ideología promovía la mentalidad de vasallaje, la carencia de un espíritu independiente, la indolencia, la falta de iniciativa, el egoísmo malicioso y la falta de sentido del honor entre los coreanos; solamente se reconocían dos beneficios: la lealtad de ciertos oficiales, y el pragmatismo que algunos pensadores promovieron en el pasado. Por otro lado, el presidente Chun Doo Huan (1980-1987), aceptó que la disciplina y el interés público eran aspectos positivos del confucianismo que se debían conservar.

Cuando se analiza el éxito económico que Corea tuvo después de la crisis de 1997, diversos economistas insistieron en que tanto la educación de alto nivel como la facilidad para el entrenamiento de la fuerza de trabajo son características esenciales para que tal éxito fuera posible. Los coreanos tienen profundamente arraigada la idea de que la educación de alto nivel es la clave para poder aspirar a superarse en el ámbito social y económico. Como consecuencia, las familias coreanas en general acostumbran sacrificarse y reservar una gran parte (si no es que todos) de sus ahorros para invertirlos en la educación de los hijos. Es así como durante los años 60, 80 y en la actualidad existe una sobreoferta de gente graduada a nivel de posgrado, con el consecuente crecimiento del desempleo y la subutilización de los recursos humanos.

En cuanto a la vida laboral en las empresas, los valores de lealtad a la familia (en este caso a la empresa), la confianza y fidelidad entre amigos, la aceptación de los niveles jerárquicos y la obediencia a la autoridad son esenciales en el trato interpersonal.

Con respecto al ámbito doméstico podemos decir que, hasta cierto punto, los roles han cambiado. Desde 1950 se redujo por ley el poder de los jefes de familia y se mejoró la posición de la mujer con respecto a las herencias y los 
derechos legales en caso de divorcio. Además la administración del presidente Kim Dae-Jung ha iniciado y llevado a la práctica diversas iniciativas para la defensa y superación de las mujeres en todos los ámbitos sociales. Aun así, el patrón de solidaridad familiar confuciano está todavía muy arraigado. Los ritos correspondientes a la conservación del linaje y la reverencia a los ancestros son todavía muy significativos, pues reafirman los lazos y la situación familiar frente a la sociedad.

El crecimiento en el sector urbano ha cambiado el ambiente físico de las familias, pues los apartamentos han reemplazado a las casas tradicionales y separado las ramas familiares. De hecho, la estructura de éstas se ha extendido geográficamente aunque los hijos tienden a permanecer en las proximidades de la casa de los padres.

Es así que a pesar de la influencia externa, los valores familiares e interpersonales de los coreanos se han conservado de una manera que no es la del pasado pero que siguen consistiendo en la piedad filial, el respeto a los mayores, la reciprocidad en las relaciones humanas y la importancia preponderante de la educación. Además, el valor de la búsqueda de la virtud sigue predominando en los estudiantes coreanos desde el comienzo de su educación, de tal manera que son exhortados constantemente a negar sus propios intereses individuales por el avance de la familia y por el bien de la nación.

En conclusión podemos afirmar que los coreanos de hoy consideran que el confucianismo como tal ha dejado de existir entre ellos aunque, en realidad, sigue influyendo en su manera de vivir al grado de que si un extranjero entra en su sociedad puede percibir claramente un código de trato y ciertas reglas sociales que incluso los jóvenes tienden a seguir, sin dejar de presentar graves contradicciones, producto de la influencia occidental que se da a través de los medios masivos de comunicación y por la migración golondrina de una gran parte de la población coreana.

\section{Bibliografía}

Deuchler, Martina, "Introduction" y "Conclusion", The Confucian Transformation of Korea, Harvard University Press 1984.

Haboush, Ja Hyun Kim, "The Confucianization of Korean Society", en Gilbert Rozman, ed., The East Asian Region: Confucian Heritage and Its Moder Adaptation, Princeton University Press, Princeton, 1991.

NJ Koh, Byong-Ik, "Confucianism in Asia's Modern Transformation”, Korea Journal 32:4, pp. 46-64, invierno 1992.

http://www.newadvent.org/cathen/04223b.htm

Plais, James B, "Confucianism and the Aristocratic/ Bureaucratic Balance in Korea", Harvard Journal of Asiatic Studies, 44:2, pp. 427-468, 1984.

Robinson Michael, "Perceptions of Confucianism in the Twentieth Century Korea" en Gilbert Rozman, op. cit. T: 